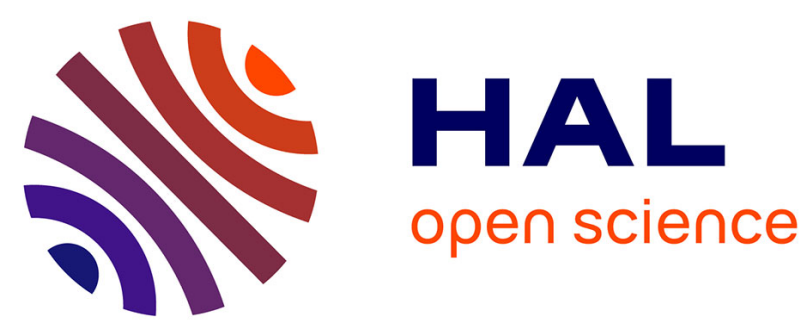

\title{
Segmental Series and Size: Clade-Wide Investigation of Molar Proportions Reveals a Major Evolutionary Allometry in the Dentition of Placental Mammals
}

Guillaume Billet, Jérémie Bardin

\section{- To cite this version:}

Guillaume Billet, Jérémie Bardin. Segmental Series and Size: Clade-Wide Investigation of Molar Proportions Reveals a Major Evolutionary Allometry in the Dentition of Placental Mammals. Systematic Biology, 2021, 10.1093/sysbio/syab007 . hal-03180738

\section{HAL Id: hal-03180738 \\ https: / hal.sorbonne-universite.fr/hal-03180738}

Submitted on 25 Mar 2021

HAL is a multi-disciplinary open access archive for the deposit and dissemination of scientific research documents, whether they are published or not. The documents may come from teaching and research institutions in France or abroad, or from public or private research centers.
L'archive ouverte pluridisciplinaire HAL, est destinée au dépôt et à la diffusion de documents scientifiques de niveau recherche, publiés ou non, émanant des établissements d'enseignement et de recherche français ou étrangers, des laboratoires publics ou privés. 
Running head: ALLOMETRY OF MOLAR PROPORTIONS IN PLACENTALS

Segmental series and size: clade-wide investigation of molar proportions reveals a major evolutionary allometry in the dentition of placental mammals

GUILLAUME BILLET ${ }^{1, *}$ AND JEREMIE BARDIN ${ }^{2}$

${ }^{1}$ Centre de Recherche en Paléontologie - Paris, CR2P, Muséum national d'Histoire naturelle, CNRS, Sorbonne Université, 8 rue Buffon 75005 Paris, France

${ }^{2}$ Centre de Recherche en Paléontologie - Paris, CR2P, Sorbonne Université, Muséum national d'Histoire naturelle, CNRS, T.46-56, E.5, case 104, 4 place Jussieu, 75252 Paris cedex 05, France

*Corresponding author:

Guillaume BILLET

CR2P, MNHN, 8 rue Buffon 75005 Paris, France

Email address: guillaume.billet@mnhn.fr

Telephone: +33140793814 
Abstract.-Iterative segments such as teeth or limbs are a widespread characteristic of living organisms. While their proportions may be governed by similar developmental rules in vertebrates, there is no emerging pattern as regards their relation to size. Placental mammals span eight orders of magnitude in body size and show a wide spectrum of dietary habits associated with size and reflected in their dentitions, especially molars. Although variation in size constitutes an important determinant for variation in biological traits, few major allometric trends have been documented on placental molars so far. Molar proportions have been intensively explored in placentals in relation to developmental models, but often at a small phylogenetic scale. Here, we analyzed the diversity of upper molar proportions in relation to absolute size in a large sample of placental species $(n=286)$ encompassing most of the group's dental diversity. Our phylogenetically informed analyses revealed a twofold pattern of evolutionary integration among upper molars: while molars covary in size with each other, their proportions covary with the absolute size of the entire molar field. With increasing absolute size, posterior molars increase in size relative to anterior ones, meaning that large-sized species have relatively large rear molars while the opposite is true for smallsized species. The directionality of proportional increase in the molar row exhibits a previously unsuspected allometric patterning among placentals, showing how large-scale variations in size may have influenced variation in dental morphology. This finding provides new evidence that processes regulating the size of individual molars are integrated with overall patterns of growth and calls for further testing of allometric variation in the dentition and in other segmental series of the vertebrate body.

Keywords: Size, Dentition, Evolution, Segmentation, Phylogeny, Model 
Placental mammals repeatedly evolved a wide range of body sizes in their history and span over eight orders of magnitude in size today (Alroy 1998; Baker et al. 2015; Price and Hopkins 2015; Bokma et al. 2016). Allometry, the size-related changes of traits, constitutes a major and pervasive pattern in morphological evolution (Gould 1966; Hallgrímsson et al. 2019), and yet it remains only sporadically documented in placentals. Scaling relationships were probably important along their diversification in size and impacted several aspects of their skull (Nummela 1995; Cardini and Polly 2013). Placentals also evolved a wide spectrum of dietary habits in association to body size (Price and Hopkins, 2015) and dental morphology (Ungar, 2010). However, although mammalian teeth have been studied intensively for their phylogenetic and functional signals, allometric relationships within their dentition have only been sparsely explored (e.g., Kurtén 1954; Gould, 1975; Singleton et al. 2011).

Within the differentiated dentition of placentals (Ungar, 2010), molars represent an outstanding model to study allometry in a segmental series. Placentals generally present three molars per jaw quadrant, which typically grade in size anteroposteriorly (e.g., Butler 1939; Polly 2007). Like other teeth, molars are serially repeated organs. Together with limbs, vertebrae and phalanges, they constitute segmental series of the body whose proportions may be governed by similar developmental rules (Kavanagh et al. 2007; Young et al. 2015; Green and Sharpe, 2015). The size of a given segment within these series tends to covary with that of adjacent segments, as proposed by the Inhibitory Cascade (IC) model for lower molars in mice (Kavanagh et al. 2007). This experimental model is based on an activator-inhibitor logic controlling sequential tooth development, with each molar inhibiting the formation of the following one. Assuming that this cascade system is the sole determinant of molar size differences along the jaw, the second molar will make up one third of the total molar area (Kavanagh et al. 2007; Polly 2007). The diversity of lower molar proportions in placentals was much studied following this finding. These subsequent studies reported varying degrees 
of adhesion to the IC model across different taxa, and found associations between molar proportions, diet and phylogeny (e.g., Hlusko et al. 2011; Wilson et al. 2012; Bernal et al. 2013, Halliday and Goswami 2013; Asahara et al. 2016; Carter and Worthington 2016; Evans et al. 2016; Roseman and Delezene 2019). However, the existence of potential allometric patterns within the large diversity of molar proportions in placentals has rarely been addressed. Two studies suggested that lower molar proportions may vary jointly with body size in a few isolated placental clades, but this was never investigated at a large phylogenetic scale within placentals (Wilson et al. 2012; Evans et al. 2016).

Here, we explore upper molar proportions in a large and phylogenetically diverse sample of placental mammals and test for an allometric pattern accompanying this diversity. By focusing on the upper molars, we also assess how well the IC model, which was originally proposed on lower molars, fits variation observed in the upper jaw. Our results highlight a previously overlooked evolutionary link between the absolute size of molars and their proportions that adds to our knowledge of the sequential competition faced by adjacent teeth (Kavanagh et al. 2007). The discovery of this allometric gradient in the tooth row strongly emphasizes the value of exploring scaling patterns among other segmental series within the body of vertebrates and other living organisms.

\section{MATERIAL \& METHODS}

\section{Specimen Selection}

We measured the size of the three upper molars (M1, M2, M3) in complete molar rows of 311 extant and fossil specimens belonging to 199 extant and 100 extinct placental species, in 277 genera. 286 species were represented by one specimen, and 13 species by 2 specimens. The intraspecific variation of molar proportions, generally low in placental species (Vitek et al., 2020), was assumed to be negligible in comparison to the magnitude of the interspecific 
variation related to allometry for Placentalia (see Supplementary Material available on Dryad, http://dx.doi.org/10.5061/dryad.dfn2z34xq). The sample covered most extant placental orders, some being excluded for being edentulous or enamel-free taxa (Cingulata, Pilosa, Tubulidentata), having high-crowned teeth (Lagomorpha) (see Gomes Rodrigues et al., 2017 for reasoning), or supernumerary molars (Sirenia). The sample was mostly composed of original specimens or casts present in the collections of the Muséum national d'Histoire naturelle, Paris (MNHN), while images for the remaining specimens were collected from the literature (see Supplementary Material available on Dryad).

\section{Measurements}

Molar size was quantified by measuring area in occlusal view using the software Fiji (Schindelin et al. 2012) on scaled images of upper molar rows. For MNHN specimens (original or cast), images of molar occlusal surfaces were taken with a Canon® EOS 60D camera fitted with a Canon ${ }^{\circledR}$ EF Macro-Lens $100 \mathrm{~mm}, \mathrm{f} / 2.8$. The camera was attached to a Giottos® camera tripod (VT-901). The occlusal surface and the lens of the camera were oriented parallel to each other, in the horizontal plane (controlled by a leveling device). A scale was placed parallel to, and at the same distance from the lens as, the basal plane of the crown (i.e., cementoenamel junction), as in previous studies (Gómez-Robles et al. 2007). Measurements for non-MNHN specimens were made on scaled illustrations available in the literature. On the scaled images, molar outlines were delineated at the cementoenamel junction using the tool Freehand Selection in Fiji. The area of each molar was measured three times following this method and then averaged. Three variables were obtained: M1area, M2area, and M3area. From these, three variables were computed for further analyses: M2area/M1area; M3area/M1area; log (size) = log (M1area + M2area + M3area). The latter 
variable thus measured the absolute size of the molar field (total molar area). The three variables are noted $\mathrm{M} 2 / \mathrm{M} 1, \mathrm{M} 3 / \mathrm{M} 1$ and $\log$ (size) hereafter.

In some taxa, molars experienced some degree of labial overlap that partially hid small parts of the parastylar region or mesial edge of the tooth. In such case, the molar outline in this region was drawn by following a straight path between the non-hidden parts.

\section{Tree building}

A fully dichotomous composite cladogram was constructed for phylogenetically-informed statistical analyses (see below). It is largely overlapping with that of Billet and Bardin (2019) and its construction is based on the same publications and rationale. We used the phylogenetic patterns obtained by Meredith et al. (2011) and Wible et al. (2009) for interordinal relationships of extant taxa and for the placement of successive fossil outgroups to crown Placentalia, respectively. We used a combination of sources for dating the divergences on the reconstructed composite cladogram and followed the same rationale as Billet and Bardin (2019) for placing fossils (see Supplementary Material available on Dryad).

\section{Statistical analyses}

Statistical analyses were performed on the complete sample (Placentalia), as well as on selected clades within Placentalia, with $\mathrm{n} \geq 15$ sampled species. The relationships between molar proportions, i.e. M2/M1 and M3/M1, were first analyzed using both ordinary Reduced Major Axis (RMA) and Phylogenetic Reduced Major Axis (PRMA) regressions respectively with the R packages $\operatorname{rgr}$ (Garrett, 2013) and phytools (Revell 2012). RMA and PRMA were used as none of the variables are known to have a direct influence on each other. Confidence of RMA is estimated with $95 \%$ confidence intervals, p-values of f-tests and Pearson 
correlation coefficient. PRMA confidence is based on the same metrics except for confidence intervals that are not available.

The influence of the size of the molar field (log (size)) on M2/M1 and M3/M1 was quantified using both Generalized Least Squares (GLS) and Phylogenetic GLS (PGLS) regressions with the R package caper (Orme et al. 2013). Using maximum likelihood, we simultaneously optimized Pagel's lambda to integrate a variable phylogenetic signal. GLS and PGLS robustness was estimated with standard error of estimates, $\mathrm{p}$-values of corresponding t-tests and $\mathrm{R}^{2}$; their relative adequacy to the data was compared using the Akaike Informative Criterion (AIC; Akaike 1974). It should be noted that the $\mathrm{R}^{2}$ of a PGLS is hardly comparable with that of an Ordinary Least Squares regression as their covariance matrices are respectively the covariance matrix derived from the model of trait change and the phylogeny and the identity matrix. In order to visualize the correlated evolution of log (size) and molar proportions on the cladogram, we used the function contMap of phytools (Revell 2012) that optimizes ancestral node values that are the most likely under a Brownian motion evolution. Finally, to investigate the variation of the regression outcomes due to phylogenetic uncertainty in placentals, we performed PGLS on altered topologies. Using phangorn (Schliep 2011), we ran 100 times 50 topological changes by Nearest Neighbour Interchange rearrangement.

\section{RESULTS}

The distribution of specimens in the morphospace is concentrated mainly in one direction, suggesting that molar sizes largely covary (Fig. 1a), but this direction is shifted towards larger M2 values relative to the proposed IC model (Kavanagh et al. 2007; Polly 2007) and shows a weaker slope than the latter (see Supplementary Material available on Dryad). In the morphospace of molar proportions, taxa with the largest molar field generally have relatively 
large posterior molars $(\mathrm{M} 1<\mathrm{M} 2<\mathbf{M 3}$ and $\mathrm{M} 1<\mathbf{M} 2>\mathrm{M} 3)$ while smaller taxa show a relatively larger M1 (M1>M2>M3) (Fig. 1a).

The phylogenetic co-distributions of the molar proportions and of the absolute size of the molar field (log (size)) confirm this pattern: when the absolute size of the molar field increases in a clade, both ratios M3/M1 and M2/M1 most often increase as well (Fig. 2 and see Supplementary Material available on Dryad). These co-distributions are characterized by multiple events of increases and decreases of M2/M1, M3/M1 and log (size) during placentals' evolutionary history. Generalized Least Square analyses, whether phylogenetically informed (PGLS) or not (GLS), show a strong statistical support for correlated evolution of the absolute size of the molar field and molar proportions (Table 1). Bivariate plots of the proportions and size variables (Fig. 1b-c) show that specimens belonging to various clades cluster in the extremal parts of the morphospace, and thus discard the possibility of a Felsenstein's worst case scenario (singular evolutionary events; Uyeda et al. 2018) at the Placentalia level. The Akaike scores indicate that the favored regression model for both ratios is the PGLS one (Table 1). The slope of the regression of M3/M1 on log (size) is more than twice the slope of the regression of M2/M1 on log (size), in both GLS and PGLS analyses (Fig. 1b-c \& Table 1). This shows that M3/M1 increases more than twice as fast as M2/M1 with an increasing log (size). The intercept values, one of which has poor statistical support (PGLS, M3/M1 vs log (size)), are much higher for the regressions of M2/M1 on log (size) than for those of M3/M1 on log (size). Besides, the slope values are lower in the PGLS than in the GLS analyses of the same variables while it is the opposite for the intercept values, indicating that the consideration of phylogenetic relationships pulls the regression line higher and makes it less steep (Fig. 1b-c \& Table 1). At a lower taxonomic level, the Afrotheria, Primates and Glires also show a well-supported correlated evolution for the ratios M2/M1 \& M3/M1 with the absolute size of the molar field, while Chiroptera show an opposite trend for 
M3/M1 (see further comments on variations among clades in Supplementary Material available on Dryad).

The analyses on altered topologies also show a robust statistical support, for both regressions of M2/M1 on $\log$ (size) and M3/M1 on $\log$ (size). Both the slope and intercept values of the randomized analyses remain very close to the ones found by the PGLS analyses on the baseline cladogram (Table 1 and see Supplementary Material available on Dryad). The distribution of the p-values of t-tests are very low except for intercepts of a few runs for the regression of M3/M1 on log (size). The results of the PGLS analyses on the entire Placentalia sample are thus not prone to change when the phylogenetic relationships are slightly changed.

\section{DISCUSSION}

\section{Evolutionary Allometry of Molar Proportions: Robustness and Scope}

The large diversity of upper molar proportions within placentals is accompanied by an allometric pattern along their favored direction of covariation: placental mammals with large dentitions present larger posterior molars relative to the anterior one. The area of M2 and even more that of M3 increases faster than that of M1 with increasing size at the macroevolutionary level (Figs. 1b-c and see Supplementary Material available on Dryad). This is congruent with the well-known high variability in size of third molars, which are the last to develop (Gould and Garwood 1966; Bernal et al. 2013). An allometric pattern of molar proportions was very strongly supported at the level of Placentalia, and well-supported in clades like Primates and Afrotheria. The taxonomic scale for such analyses may be important as the evolution of several independent and large-magnitude changes in size might be more likely in longexisting and diverse lineages. Clades with a lower taxonomic diversity and/or lower magnitude of size differences in our sample often show no (or less) well-supported allometric 
relationship (see Supplementary Material available on Dryad). Our results seem robust to phylogenetic variations, which is important given that placental phylogeny especially suffers from uncertainties concerning the position of fossil lineages (Springer et al. 2013; Beck and Baillie 2018).

Our study shows that variation in upper molar proportions across placentals deviates from the line predicted by the IC model, and maybe even slightly more than for lower molars (e.g., Kavanagh et al., 2007; Bernal et al., 2013). Antagonist molars may partly differ in their development (e.g., Hayden et al., 2020) and probably experience different spatial constraints on the palate compared to the narrow lower jaw (Renvoisé et al., 2017). Whether these factors could cause differences in proportional relationships among the upper and lower molar rows remains to be evaluated. Despite these differences, antagonist molars are often strongly integrated in both shape and size (Renaud et al., 2009; Gómez-Robles \& Polly, 2012) and molar proportions in the upper jaw often resemble those of the lower jaw (Gomes Rodrigues et al., 2017; Muizon et al., 2019). The genetic determinants of molar size variation also appear partially similar for the upper and lower jaws (Navarro \& Maga, 2019). For all these reasons, we postulate that the evolutionary allometry detected here on upper molars may be expressed similarly, but not identically, on lower molars in placentals, which echoes previous findings in isolated placental clades (Wilson et al. 2012; Bernal et al. 2013; Evans et al. 2016).

While choosing a local measure of size (molar field), we assumed that molar proportions were more closely linked to local processes than to those determining variation in overall body size or size of other organs (Hallgrímsson et al. 2019). Yet, the absolute size of molars is also roughly indicative of body sizes in mammals (e.g., Copes and Schwarz 2010). When combined with our results, this suggests that large-bodied placentals will tend to show much larger M3 and M2 than M1 and the opposite for small-bodied ones. Most extant placental taxa that lost the upper and/or lower third molar count as small- to medium-sized 
organisms (e.g., some macroscelids, chrysochlorids, bats, callitrichines monkeys, otochonid lagomorphs, carnivorans, murid and bathyergid rodents; taxa with dental displacement and ever-growing teeth not considered; Ungar 2010; Gomes Rodrigues 2015). This seems in good agreement with our results, because if small mammals tend to have relatively reduced posterior molars, they could be more prone to a loss of their upper and lower third molars. Similarly, cases of small placentals with much enlarged posterior molars relative to M1 should be rare. Apart from taxa with reduced or homodont dentitions, major exceptions to the allometric pattern are found within rhinoceroses, which have relatively small posterior molars while having a large absolute size, and in the large-sized carnivorans presenting relatively large M1, and small-to-absent M2 and M3 (e.g., felids, ursids). Stem and early diverging carnivorans with reduced-to-absent M3 and M2 were however rather small- to medium-sized placentals (Bokma et al. 2016), as predicted by the allometric pattern. Later increased specialization towards a flesh-eating diet and the anterior position of the carnassials might have caused the deviation of late diverging carnivorans from this pattern (see below). Although it is robustly supported at the placental level, the strength and direction of the allometric pattern vary within placental groups and exceptions exist. This suggests that size may represent one among several determinants of molar proportions, each one having a fluctuating influence along evolutionary branches.

\section{Potential Correlates and Mechanisms behind the Allometric Pattern}

Our work suggests a biased macroevolution of molar proportions towards relatively larger posterior molars in large-sized taxa. Potential mechanisms for this phenomenon could implicate a weaker intermolar inhibition with increasing absolute size of the molar field and/or a higher dental mesenchymal activation (Kavanagh et al. 2007; Wilson et al. 2012; 
Evans et al. 2016). Overall, this would mean a higher ratio of activator to inhibitor in taxa with a larger molar field but it is unclear if the mouse-derived IC model applies to organisms with very different life histories (e.g., larger and longer-lived organisms; Speakman 2005; Carter and Worthington 2016). Another question that arises from this is whether the allometric pattern of molar proportions detected here at the macroevolutionary scale is also expressed at a microevolutionary one, and how. Further research on the size-related variation of molar proportions will be needed within species and along ontogeny to test for expression of this allometric patterning across biological levels (Klingenberg and Zimmerman 1992; Pavlicev et al. 2008; Hlusko et al. 2011; Navarro and Maga 2018). Among other aspects, this allometric pattern may be worth investigating in relation to the genetic correlation between body size and molar width previously detected in baboons (Hlusko et al., 2006). At the macroevolutionary level, our study suggests a more complex pattern of integration among molars than previously thought, with molars covarying in size with each other, and their proportions covarying with the absolute size of the entire molar field. Like any pattern of covariation, this twofold pattern might involve complex combinations of developmental processes, genetic and environmental effects (Hallgrímsson et al. 2009; Roseman and Delezene 2019).

Potential correlates of molar proportions and thus of the detected evolutionary allometry include the configuration of neighboring premolars and the dietary habits of the taxa. In rodents, molar proportions were linked to the presence or absence of the fourth premolar (Labonne et al. 2012) which might constitute a spatial constraint on the development of the first molar. The fourth permanent premolar is absent in only one clade composed of four rodents in our sample and thus was not an important parameter. The proportions of posterior premolars and their relation to the allometry shown by molars remain to be investigated, although, for instance, species with large posterior premolars do not seem to be 
associated with a given range of molar proportions in our sample (e.g., rhinos vs pyrotheres). The timing of premolar initiation and replacement could also be an important parameter in relation to the space available for molar formation in the jaw (see below).

Molar proportions were reported to reflect dietary habits in various groups of placental mammals (Kavanagh et al. 2007; Halliday and Goswami 2013; Carter and Worthington 2016; but see also Monson et al., 2019a). Herbivorous and faunivorous forms were then found at opposite extremes of the morphospace with the former showing relatively large posterior molars (e.g., upper right corner of Fig. 1a). Diet might also be correlated to body mass with large terrestrial mammals being mostly herbivorous and small ones mostly omnivorous and carnivorous (Price and Hopkins 2015). It is therefore not surprising that both diet and size may be reflected in the diversity of molar proportions among placentals. Interestingly, the extinct hyainalourine creodonts included giant carnivorous forms with relatively large posterior molars (Borths and Stevens 2019), which agrees better with our results and contrasts with the case of carnivorans. Besides allometry, the chewing biomechanics and the various positions of the carnassial teeth in carnivorous forms (Asahara et al. 2016) may play a role in molar proportions.

One important aspect of this study is that it may imply differential growth dynamics of the anterior and posterior molars depending on the size of the molar field. It is currently unclear whether and how a different timing of initiation and/or different growth rates of posterior molars could explain diverging molar proportions (Kavanagh et al. 2007; Carter and Worthington 2016), and even more so in relation to size. With respect to their skull, mammals generally present well-marked differential growth between their face and neurocranium, known as craniofacial allometry. This allometry is present both at the evolutionary and ontogenetic levels in mammals with larger individuals having relatively larger faces than smaller ones (Cardini and Polly 2013; Cardini 2019). Large mammals could therefore be 
characterized by both relatively large faces and large posterior molars, which raises the question of shared mechanisms between these two allometric patterns. Upper molars grow sequentially, with the M3 forming last, in the posterior region of the palate formed by the maxillary bone. As a main facial component, the maxillary bone strongly increases in size during mammalian ontogeny and is much affected by the evolutionary craniofacial allometry (Cardini and Polly 2013; Cardini 2019). The forming molars and surrounding jaw are tightly integrated during development, with mechanical aspects of the growing jaw actively constraining the shape of molars (Renvoisé et al. 2017) and with dynamic bone remodeling around forming molars (Butler, 1956; Lungová et al. 2011). Knowing the spatiotemporal association between jaw and molar formations and the late completion of the posterior part of the palate in its growth sequence, one could speculate that jaws growing an overall larger size might be developmentally and mechanistically associated with a greater growth of lateforming posterior molars in comparison to anterior ones. Speculation about an association between molar proportions and jaw size is not new (e.g., Ford, 1980; Monson et al., 2019b), and links between jaw dimensions and third molar development are for instance welldocumented in humans (Kömerik et al., 2014; Marchiori et al., 2019). However, more research is needed in that direction as the validity of an association between jaw growth and molar proportions and the potential mechanisms behind it remains extremely obscure.

Overall, the allometric relationship found in our study is congruent with the idea that processes regulating the size of organs, such as individual molars, and overall patterns of growth are integrated (e.g., Shingleton 2011). This finding adds complexity to our understanding of the covariation of molar proportions and prompts further questions about the mechanisms generating this structured diversity. The current lack of mechanistic explanations should stimulate further research along with further testing of allometric patterns among other segmental systems of living organisms. 


\section{ACKNOWLEDGMENTS}

Many thanks to G. Véron, J. Lésur, J. Cuisin, C. Denys, J.-M. Pons, V. Nicolas, A. Verguin, and C. Bens (MNHN), D. Brinkman and J. Henderson (YPM), for access to specimens; H. Gomes Rodrigues (CR2P, MNHN), R. Tabuce (ISEM, Univ. Montpellier), A. Souron and P. Bayle (PACEA, Univ. Bordeaux) for help and discussion; Paleobiology Database (PBDB) for temporal data on fossils. Many thanks to L. M. Davalos, A. Sadier and M. Brasil for their very insightful comments.

\section{LITERATURE CITED}

Akaike H. 1974. A new look at the statistical model identification. IEEE Trans. Autom. Contr. 19:716-723.

Alroy J. 1998. Cope's rule and the dynamics of body mass evolution in North American fossil mammals. Science. 280(5364):731-734.

Asahara M., Saito K., Kishida T., Takahashi K., and Bessho K. 2016. Unique pattern of dietary adaptation in the dentition of Carnivora: its advantage and developmental origin. Proc. R. Soc. B. 283(1832):20160375.

Baker J., Meade A., Pagel M., and Venditti C. 2015. Adaptive evolution toward larger size in mammals. Proc. Natl. Acad. Sci. U. S. A. 112(16):5093-5098.

Beck R. M., and Baillie C. 2018. Improvements in the fossil record may largely resolve current conflicts between morphological and molecular estimates of mammal phylogeny. Proc. R. Soc. B. 285(1893):20181632. 
Bernal V., Gonzalez P. N., and Perez S. I. 2013. Developmental processes, evolvability, and dental diversification of New World monkeys. Evol. Biol. 40(4):532-541.

Billet G., and Bardin J. 2019. Serial homology and correlated characters in morphological phylogenetics: modeling the evolution of dental crests in placentals. Syst. Biol. 68(2):267280.

Bokma F., Godinot M., Maridet O., Ladevèze S., Costeur L., Solé F., Gheerbrant E., Peigné S., Jacques F., and Laurin M. 2016. Testing for Depéret's rule (body size increase) in mammals using combined extinct and extant data. Syst. Biol. 65(1):98-108.

Borths M.R., and Stevens N.J. 2019. Simbakubwa kutokaafrika, gen. et sp. nov. (Hyainailourinae, Hyaenodonta, 'Creodonta,'Mammalia), a gigantic carnivore from the earliest Miocene of Kenya. J. Vertebr. Paleontol. 39(1):e1570222.

Butler P.M. 1939. Studies of the Mammalian Dentition. Differentiation of the Post-canine Dentition. Proc. Zool. Soc. London 109(1):1-36.

Butler P.M. 1956. The ontogeny of molar pattern. Biol. Rev. 31:30-69.

Cardini A. 2019. Craniofacial allometry is a rule in evolutionary radiations of placentals. Evol. Biol. 46(3):239-248.

Cardini A., and Polly P.D. 2013. Larger mammals have longer faces because of size-related constraints on skull form. Nat. Commun. 4, 2458.

Carter K.E., and Worthington S. 2016. The evolution of anthropoid molar proportions. BMC Evol. Biol. 16(1):110.

Copes L.E., and Schwartz G.T. 2010. The scale of it all: postcanine tooth size, the taxon-level effect, and the universality of Gould's scaling law. Paleobiology. 36(2):188-203.

Evans A.R., Daly E.S., Catlett K.K., Paul K.S., King S.J., Skinner M.M., Nesse H.P., Hublin J.J., Townsend G.C., Schwartz G.T., and Jernvall J. 2016. A simple rule governs the evolution and development of hominin tooth size. Nature. 530(7591):477-480. 
Ford S.M. 1980. Callitrichids as phyletic dwarfs, and the place of the Callitrichidae in Platyrrhini. Primates. 21(1):31-43.Garrett R.G. 2013. The 'rgr' package for the R Open Source statistical computing and graphics environment - a tool to support geochemical data interpretation. Geochem-Explor. Env. A. 13(4):355-378.

Gomes Rodrigues H. 2015. The great disparity of dental structures and dynamics in rodents: new insights into their ecological diversity. In: Cox P., and Hautier L., editors.. Evolution of the Rodents: Advances in Phylogeny, Functional Morphology and Development. Cambridge University Press. P. 424-447.

Gomes Rodrigues H., Lefebvre R., Fernández-Monescillo M., Mamani Quispe B., and Billet G. 2017. Ontogenetic variations and structural adjustments in mammals evolving prolonged to continuous dental growth. R. Soc. open sci. 4(7):170494.Gómez-Robles A., Polly P.D. 2012. Morphological integration in the hominin dentition: evolutionary, developmental, and functional factors: morphological integration in the hominin dentition. Evolution. 66:10241043.

Gómez-Robles A., Martinón-Torres M., Bermúdez De Castro J.M., Margvelashvili A., Bastir M., Arsuaga J. L., Pérez-Pérez A., Estebaranz F., and Martínez L.M. 2007. A geometric morphometric analysis of hominin upper first molar shape. J. Hum. Evol. 53(3):272-285.

Gould S.J. 1966. Allometry and size in ontogeny and phylogeny. Biol. Rev. 41:587-638.

Gould S.J. 1975. On the scaling of tooth size in mammals. Am. Zool. 15(2):353-362.

Gould S.J., and Garwood R.A. 1969. Levels of integration in mammalian dentitions: an analysis of correlations in Nesophontes micrus (Insectivora) and Oryzomys couesi (Rodentia). Evolution. 23:276-300.

Green J.B., and Sharpe J. 2015. Positional information and reaction-diffusion: two big ideas in developmental biology combine. Development. 142(7):1203-1211.Hallgrímsson B., Jamniczky H., Young N.M., Rolian C., Parsons T.E., Boughner J.C., and Marcucio R.S. 2009. 
Deciphering the palimpsest: studying the relationship between morphological integration and phenotypic covariation. Evol. Biol. 36(4):355-376.

Hallgrímsson B., Katz D.C., Aponte J.D., Larson J.R., Devine J., Gonzalez P.N., Young N.M., Roseman C.C., and Marcucio R.S. 2019. Integration and the developmental genetics of allometry. Integr. Comp. Biol. 59(5):1369-1381.

Halliday T.J., and Goswami A. 2013. Testing the inhibitory cascade model in Mesozoic and Cenozoic mammaliaforms. BMC Evol. Biol. 13(1):79.

Hayden L., Lochovska K., Sémon M., Renaud S., Delignette-Muller M.L., Vilcot M., Peterkova R., Hovorakova M., and Pantalacci S. 2020. Developmental variability channels mouse molar evolution. Elife. 9:p.e50103.

Hlusko L.J., Lease L.R., and Mahaney M.C. 2006. Evolution of genetically correlated traits: tooth size and body size in baboons. Am. J. Phys. Anthropol. 131(3):420-427.Hlusko L.J., Sage R.D., Mahaney M.C. 2011. Modularity in the mammalian dentition: mice and monkeys share a common dental genetic architecture. J.Exp. Zool. 316B:21-49.

Kavanagh K.D., Evans A.R., and Jernvall J. 2007. Predicting evolutionary patterns of mammalian teeth from development. Nature. 449(7161):427-432.

Klingenberg C.P., and Zimmermann M. 1992. Static, ontogenetic, and evolutionary allometry: a multivariate comparison in nine species of water striders. Am. Nat. 140(4):601-620.

Kömerik N., Topal O., Esenlik E., and Bolat E. 2014. Skeletal facial morphology and third molar agenesis. J. Res. Pract. Dent. 2014:452422. Kurtén B. 1954. Observations on allometry in mammalian dentitions: its interpretation and evolutionary significance. Act. Zool. Fenn. 85.

Labonne G., Laffont R., Renvoisé E., Jebrane A., Labruère C., Chateau-Smith C., Navarro N., and Montuire S. 2012. When less means more: evolutionary and developmental hypotheses in rodent molars. J. Evol. Biol. 25(10):2102-2111. 
Lungová V., Radlanski R.J., Tucker A.S., Renz H., Míšek I., and Matalová E. 2011. Tooth-bone morphogenesis during postnatal stages of mouse first molar development. J. Anat. 218(6):699-716.

Marchiori D.F., Packota G.V., and Boughner J.C. 2019. Initial third molar development is delayed in jaws with short distal space: An early impaction sign?. Arch. Oral Biol. 106:104475.

Meredith R.W., Janecka J.E., Gatesy J., Ryder O.A., Fisher C.A., Teeling E.C., Goodbla A., Eizirik E., Simao T.L.L., Stadler T., Rabosky D.L., Honeycutt R.L., Flynn J.J., Ingram C.M., Steiner C., Williams T.L., Robinson T.J., Burk-Herrick A., Westerman M., Ayoub N.A., Springer M.S., Murphy W.J.2011. Impacts of the Cretaceous Terrestrial Revolution and KPg extinction on mammal diversification. Science. 334(6055):521-524. Monson T.A., Boisserie J.-R., Brasil M.F., Clay S.M., Dvoretzky R., Ravindramurthy S., Schmitt C.A., Souron A., Takenaka R., Ungar P.S., Yoo S., Zhou M., Zuercher M.E., and Hlusko L.J. 2019a. Evidence of strong stabilizing effects on the evolution of boreoeutherian (Mammalia) dental proportions. Ecol. Evol. 9:7597-7612.

Monson T.A., Coleman J.L., and Hlusko L.J. 2019b. Craniodental allometry, prenatal growth rates, and the evolutionary loss of the third molars in New World monkeys. Anat. Rec. 302(8):1419-1433

de Muizon C., Billet G., Ladevèze S. 2019. New remains of kollpaniine "condylarths" (Panameriungulata) from the early Palaeocene of Bolivia shed light on hypocone origins and molar proportions among ungulate-like placentals. Geodiversitas. 41(1):841-874.

Navarro N., and Maga A.M. 2018. Genetic mapping of molar size relations identifies inhibitory locus for third molars in mice. Heredity. 121(1):1-11.

Nummela S. 1995. Scaling of the mammalian middle ear. Hear. Res. 85(1-2):18-30. 
Orme D., Freckleton R., Thomas G., Petzoldt T., Fritz S., Isaac N., Pearse W. 2018. caper: comparative analyses of phylogenetics and evolution in R. Methods Ecol. Evol. 3:145-151.

Pavlicev M., Kenney-Hunt J.P., Norgard E.A., Roseman C.C., Wolf J.B., Cheverud J.M. 2008. Genetic variation in pleiotropy: differential epistasis as a source of variation in the allometric relationship between long bone lengths and body weight. Evolution. 62:199-213.

Polly P.D. 2007. Development with a bite. Nature. 449(7161):413-414.

Price S.A., and Hopkins S.S. 2015. The macroevolutionary relationship between diet and body mass across mammals. Biol. J. Linn. Soc. Lond. 115(1):173-184.

Renaud S., Pantalacci S., Quéré J.-P., Laudet V., and Auffray J.-C. 2009. Developmental constraints revealed by co-variation within and among molar rows in two murine rodents. Evol. Dev. 11:590-602.Renvoisé E., Kavanagh K.D., Lazzari V., Häkkinen T.J., Rice R., Pantalacci S., and Jernvall J. 2017. Mechanical constraint from growing jaw facilitates mammalian dental diversity. Proc. Natl. Acad. Sci. U.S.A. 114(35):9403-9408.

Revell L.J. 2012. phytools: An R package for phylogenetic comparative biology (and other things). Methods Ecol. Evol. 3:217-223.

Roseman C.C., and Delezene L.K. 2019. The Inhibitory Cascade Model is Not a Good Predictor of Molar Size Covariation. Evol. Biol. 46(3):229-238.

Schindelin J., Arganda-Carreras I., Frise E., Kaynig V., Longair M., Pietzsch T., Preibisch S., Rueden C., Saalfeld S., Schmid B., Tinevez J.-Y., White D.J., Hartenstein V., Eliceiri K., Tomancak P., and Cardona A. 2012. Fiji: an open-source platform for biological-image analysis. Nat. Methods 9(7):676-682.

Schliep K.P. 2011. phangorn: Phylogenetic analysis in R. Bioinformatics. 27(4):592-593.

Shingleton A.W. 2011. Evolution and the regulation of growth and body size. In: Flatt T., and Heyland A., editors. Mechanisms of life history evolution. The genetics and physiology of life history traits and trade-offs. Oxford: Oxford University Press. p. 43-55. 
Singleton M., Rosenberger A.L., Robinson C., and O'Neill R. 2011. Allometric and metameric shape variation in Pan mandibular molars: a digital morphometric analysis. Anat. Rec. 294(2):322-334.

Speakman J.R. 2005. Body size, energy metabolism and lifespan. J. Exp. Biol. 208(9):17171730.

Springer M.S., Meredith R.W., Teeling E.C., and Murphy W.J. 2013. Technical comment on “The placental mammal ancestor and the post-K-Pg radiation of placentals". Science. 341 (6146):613.

Ungar P.S. 2010. Mammal teeth: origin, evolution, and diversity. JHU Press.

Uyeda J.C., Zenil-Ferguson R., and Pennell M.W. 2018. Rethinking phylogenetic comparative methods. Syst. Biol. 67(6):1091-1109.

Vitek N.S., Roseman C.C., and Bloch J.I. 2020. Mammal molar size ratios and the inhibitory cascade at the intraspecific scale. Integr. Comp. Biol. obaa020. Wible J.R., Rougier G.W., Novacek M.J., and Asher R.J. 2009. The eutherian mammal Maelestes gobiensis from the Late Cretaceous of Mongolia and the phylogeny of Cretaceous Eutheria. Bull. Am. Mus. Nat. Hist. 327:1-123.

Wilson L.A., Madden R.H., Kay R.F., and Sánchez-Villagra M.R. 2012. Testing a developmental model in the fossil record: molar proportions in South American ungulates. Paleobiology 38(2):308-321.

Young N.M., Winslow B., Takkellapati S., Kavanagh K. 2015. Shared rules of development predict patterns of evolution in vertebrate segmentation. Nat. Commun. 6(1):1-7.

The authors declare no conflict of interest. 


\section{SUPPLEMENTARY MATERIAL}

Supplementary material, including data files and/or online-only appendices, can be found in the Dryad data repository at http://datadryad.org, http://dx.doi.org/10.5061/dryad.dfn2z34xq.

FIGURES \& TABLES
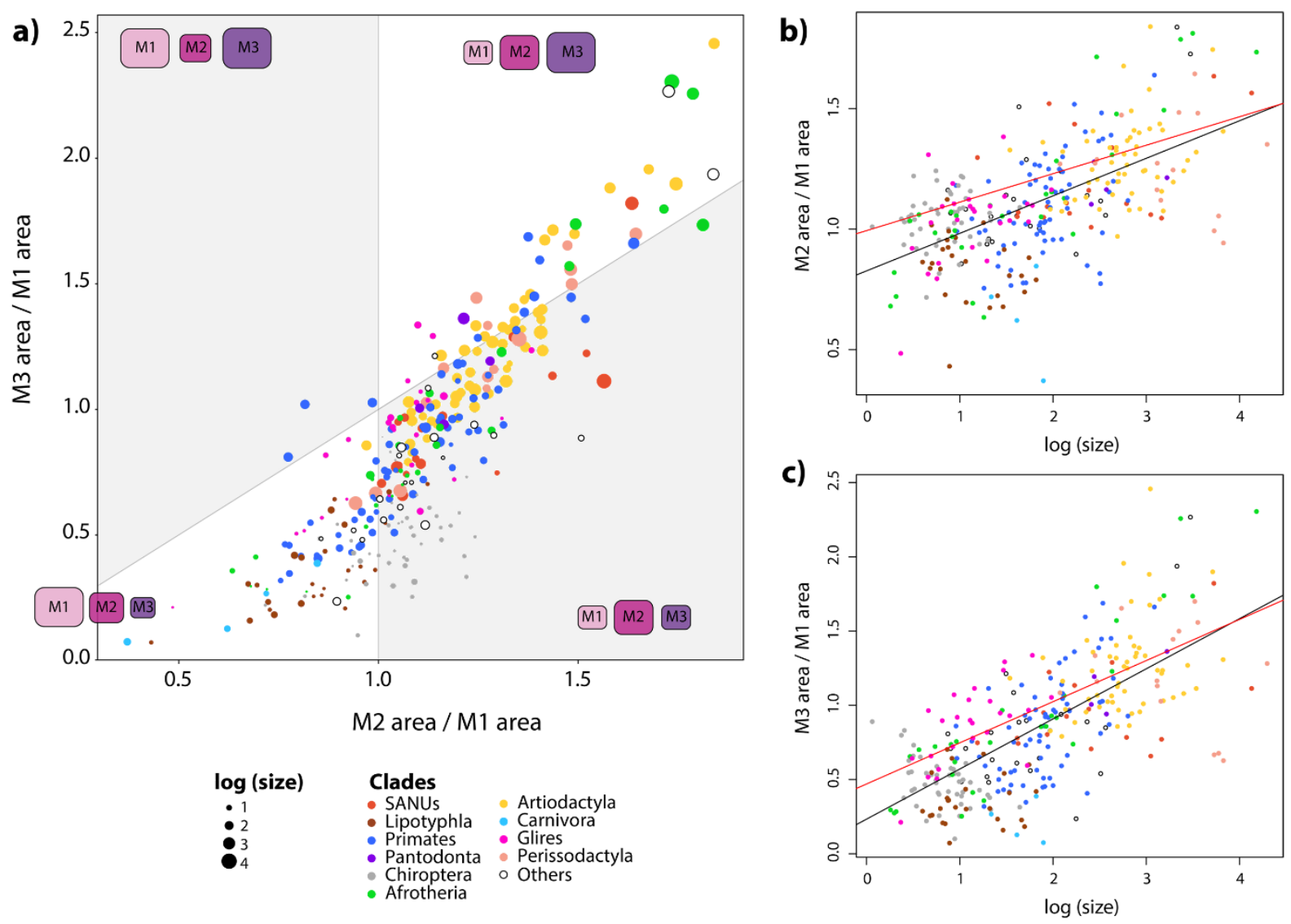

FIGURE 1. Diversity of molar proportions and relation to size. a) Molar proportions in the IC model morphospace ( $\mathrm{N}=311$ specimens). The diameter of points is proportional to the size of the molar field (log (size)) (size of dots in the caption is indicative). b) Graphical relationships between M2/M1 and log (size), and c) M3/M1 and log_size, with GLS (black) and PGLS (red) regression lines (see text \& Table 1). Abbreviation: SANUs = South American native ungulates. 

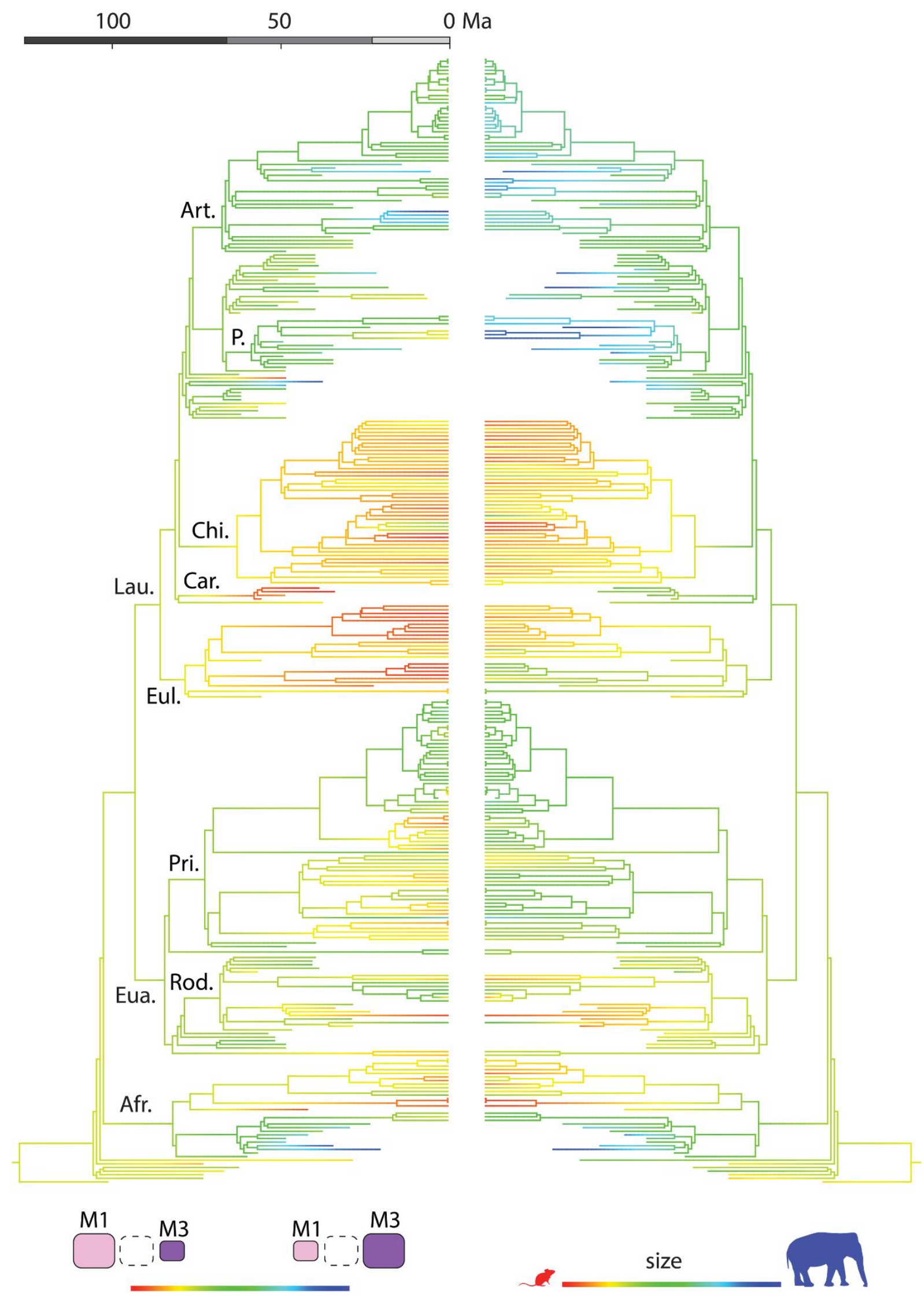

FIGURE 2. Phylogenetic co-distribution of molar proportions (M3/M1) and size of the molar field (log (size)) reconstructed on the dated cladogram (see text). Abbreviations: Afr., 
Afrotheria; Art., Artiodactyla; Car., Carnivora; Chi., Chiroptera; Eua., Euarchontoglires; Eul., Eulipotyphla; Lau., Laurasiatheria; P., Perissodactyla; Pri., Primates; Rod., Rodentia. Silhouettes from phylopic.org

TABLE 1. Results of GLS and PGLS regressions with molar proportions as the dependent variables and the size of the molar field $(\log ($ size $))$ as the independent variable in Placentalia.

\begin{tabular}{|c|c|c|c|c|c|c|c|c|c|c|}
\hline & Interc. & $\begin{array}{l}\text { Std error } \\
\text { interc. }^{\mathrm{a}}\end{array}$ & $\begin{array}{l}\mathrm{P} \text { value } \\
\text { interc. }\end{array}$ & Slope & $\begin{array}{c}\text { Std. } \\
\text { error } \\
\text { slope }^{b}\end{array}$ & $\begin{array}{c}\mathrm{P} \text { value } \\
\text { slope }\end{array}$ & $\begin{array}{l}\text { Res. } \\
\text { Std. } \\
\text { error }^{c}\end{array}$ & AIC & Lambda & $\mathrm{R}^{2}$ \\
\hline \multicolumn{11}{|l|}{ GLS } \\
\hline M2/M1 log (size $)$ & 0.827 & 0.024 & $4 \mathrm{e}-107$ & 0.156 & 0.012 & $1 e-31$ & 0.187 & -152.93 & & 0.36 \\
\hline M3/M1 log $($ size $)$ & 0.233 & 0.040 & $1 \mathrm{e}-08$ & 0.337 & 0.019 & $2 \mathrm{e}-47$ & 0.309 & 157.47 & & 0.49 \\
\hline \multicolumn{11}{|l|}{ PGLS } \\
\hline M2/M1 log (size $)$ & 0.993 & 0.108 & $<2 \mathrm{e}-16$ & 0.118 & 0.02 & $5 e-09$ & 0.0284 & -264.74 & 0.96 & 0.102 \\
\hline $\mathrm{M} 3 / \mathrm{M} 1 \sim \log ($ size $)$ & 0.47 & 0.161 & $4 e-03$ & 0.277 & 0.031 & $<2 \mathrm{e}-16$ & 0.042 & 30.9 & 0.925 & 0.204 \\
\hline
\end{tabular}

aintercept.

${ }^{\mathrm{b}} \mathrm{Standard}$ error for the slope.

${ }^{c}$ Residuals standard error. 